\title{
Research on Vertical Coupling Dynamics of Monorail Vehicle at Finger-Band
}

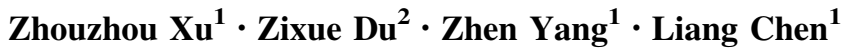

Received: 20 July 2017/Revised: 2 September 2017/Accepted: 4 September 2017/Published online: 13 September 2017

(C) The Author(s) 2017. This article is an open access publication

\begin{abstract}
In view of the fact that exhibits monorail transportation in recent years, the good situation and the lack of straddle-type monorail vehicle vertical dynamics research, the key problems of vertical vibration were studied in this paper: The vertical coupling is between walking tires and finger-band. A dynamic model based on the vertical equivalent stiffness of tire is proposed, the force mode of the tire is determined through the comparison calculation and the dynamics model between walking tires and finger band was established on ADAMS Dynamics Software. By dynamic calculation, the vibration of four running wheels in time and frequency domains is obtained, and the vibration of the front axle of the front bogie is studied in detail; the correctness of the model is confirmed by comparing with the real vehicle test. Finally, the limitations of this paper and the direction of follow-up work are discussed.
\end{abstract}

Keywords Monorail - Vertical coupling dynamics . Finger-band equivalent $\cdot$ Stiffness $\cdot$ Adams

\section{Introduction}

Since the opening of the Chongqing metro line 2 in 2004, the monorail has the advantages like small turning radius, small footprint, strong climbing ability, low noise, comfort, low

Zhouzhou Xu

33243665@qq.com

1 Chongqing Jiaotong University, Chongqing, China

2 School of Mechanical and Vehicular Engineering, Chongqing Jiaotong University, Chongqing, China

Editor: Eryu Zhu cost (only about metro's 1/3-1/2). Monorail transporation got wide acclaim. In 2011, Chongqing line 3 with independently developed equipment and technology has been put into operation, which indicates that light rail technology in China is approaching maturity. The successful operation of large-capacity monorail transportation in Chongqing indicates that the technology of large-scale and large-span straddle-type monorail transportation has matured and formed a demonstration and promotion effect. Besides Chongqing, Guiyang, Liupanshui began planning for investment in the construction of straddle-type monorail transportation, Indonesia, India, Thailand, Malaysia, Pakistan and other countries are also in the planning of straddletype monorail transportation [1].

Although the monorail was put in operation in 1970s, it has not been accepted much in the world for a long time; The maximum distance of the monorail operated in the whole world was less than $100 \mathrm{~km}$ until 2004, which is the cause that its research is not comprehensive, especially on straddletype monorail track vertical coupling dynamics, so far, there were very few studies, and the works about the vertical dynamics of straddle-type monorail vehicle were almost zero.

As a standard of public transport, the vertical dynamic action of monorail determines many problems like the safety of train operation, the riding comfort and the vertical force of rail beam [2,3]. The vertical dynamics is mainly caused by the interaction of the rail beam and the body (bogie), and the surface roughness of the track beam is the mechanism of its formation. The straddle-type monorail track beam is divided into two kinds of PC beam (prestressed reinforced concrete beam and steel structure beam), they are all prefabricated and finished, and so the surface smoothness is very good. (At least they are close to the US road A road surface, but because there is no relevant research, so we lack specific data.) The gap between 
the beam and the beam, which called finger-band, is considered to be the largest vertical excitation source in the track beam, so if we want to study the vertical dynamics of straddle-type monorail, we must study its vertical dynamics at the finger-band. [4]

\section{The Structure of Finger-Band}

The finger-band is a bridge connecting different track beams, and its structure and mechanical model are shown in Fig. 1. Each set of finger-band consists of two plates of same structure. The finger-band is slightly wider than the running wheel, which fits exactly with the special structure of the two tires running side-by-side on each axle of the bogie. When the monorail vertical passes through the finger plate, each finger-band plate group carries the side of the traveling wheel. The finger-band is made up of steel plates, it is about $4 \mathrm{~cm}$ thick and fixed on the base of the concrete, it can be considered as a rigid body, and so the deformation of the finger-band is not considered in this paper $[5,6]$.
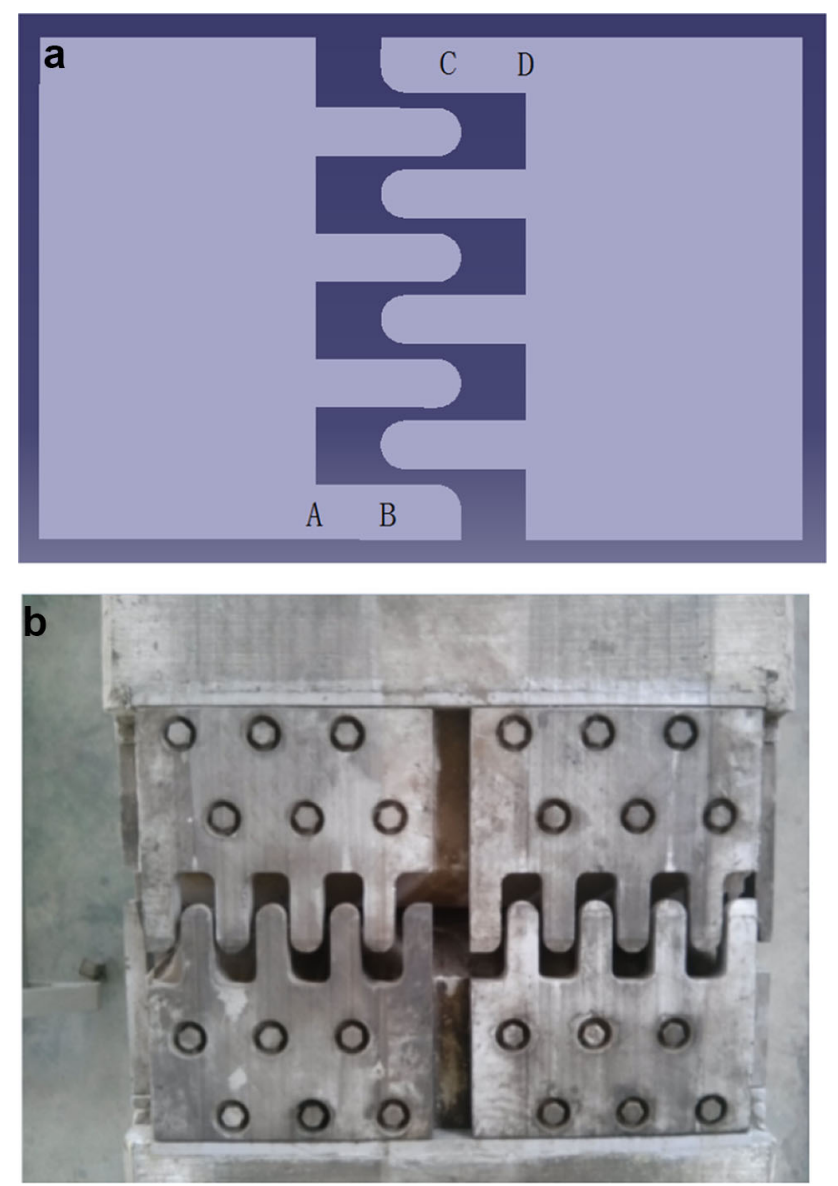

Fig. 1 a structural model diagram of finger-band, b the photograph of finger-band

\section{The Dynamics Model of Running Wheel}

As the running wheel uses rubber tires, the tire parts of the tire are subjected to uneven pressure during the crossing of the finger-band, resulting in a change in the amount of deformation and a vertical vibration of the tire $[7,8]$.

The force of the rubber tire is quite complex, and the tire is not uniform under the force of the finger-band. Therefore, the actual deformation of the tire at the finger plate cannot be explored by the force and deformation of each layer of the tire rubber. The force acting on a monorail vehicle passing through the finger-band is simulated by applying equal force on each axis of the bogie in this paper [9-12].

Compared to the steel wheel rails of ordinary trains, the wheel-rail coupling force of the monorail vehicle is much slower when rubber tracks are used on the vehicle $[13,14]$. The material, physical and geometrical parameters of the wheel are shown in Tables 1 and 2. When the tire is running on a common beam, its ground mark average, but when it is running across the finger-band, as there is a gap in the finger-band, it must have uneven deformation at the ground, in the gap, it's no compressed, the original pressure of the tire will be released because there is no compression, but at the fingers, when the compression of the finger will be increased and the center of the tire will sag. The pressure in the vertical body (weight) unchanged, that is reflected in its vertical equivalent stiffness is smaller.

The original vertical stiffness of tire is: $k 1=1,250,000 \mathrm{~N} / \mathrm{M}$, and at the finger-band, it is assumed that the equivalent stiffness has changed to: $k 2=\gamma k 1$.

ABAQUS was used to calculate the grounding mark of tire under static pressure, as shown in Fig. 2. When the tire is subjected to downward pressure of $5500 \mathrm{~kg}$, the grounding mark is about $65,400 \mathrm{~mm}^{2}$ and the mark is near rectangular. The tire is $240 \mathrm{~mm}$ wide, and the imprint is about $270 \mathrm{~mm}$ long. Known as the finger-band, the overall length of the finger is $146 \mathrm{~mm}$, and it can be thought that when the tire passes through the finger-band region at regular intervals, the $\gamma$ varies according to a rule; in order to simplify the calculation, it is set to do a uniform change, and its size can be between 1 and 0.75 . (The actual situation is that, because the rubber tire tread rubber molecular interaction, deformation at the gap can not be fully released, so the gamma should be $>0.75$. Because this experiment cannot be done, the $\gamma$ cannot be ascertained; here is the limit.)

According to the maximum value of the tire equivalent stiffness $(\gamma=0.75)$, If there is no vertical displacement of the bogie, the variation of the tire force is

$\Delta F=\Delta \gamma \cdot k_{1} \cdot x=13750 \mathrm{~N}$

where $x$ is the tire deformation under full load. 
Table 1 The material parameter of running tire

\begin{tabular}{lllll}
\hline Parameter & $C_{10} / \mathrm{MPa}$ & $C_{01} / \mathrm{MPa}$ & $D_{1} / \mathrm{MPa}$ & Density $/\left(\mathrm{Kg} / \mathrm{m}^{3}\right)$ \\
\hline Tread rubber & 0.428 & 0.107 & 0.001 & 1113 \\
Sidewall adhesive & 0.326 & 0.082 & 0.001 & 1107 \\
Cord rubber & 0.581 & 0.145 & 0.001 & 1168 \\
Triangular rubber & 0.401 & 0.102 & 0.001 & 1108 \\
\hline
\end{tabular}

Table 2 Section geometry parameter of running tyre

\begin{tabular}{ll}
\hline Mas of tire $/ \mathrm{kg}$ & 50 \\
Diameter of tire $/ \mathrm{mm}$ & 1004 \\
Width of tire $/ \mathrm{mm}$ & 340 \\
Aspect ratio of tire section & 0.85 \\
Diameter of rim/mm & 424 \\
Tread pattern & Longitudinal groove pattern \\
\hline
\end{tabular}

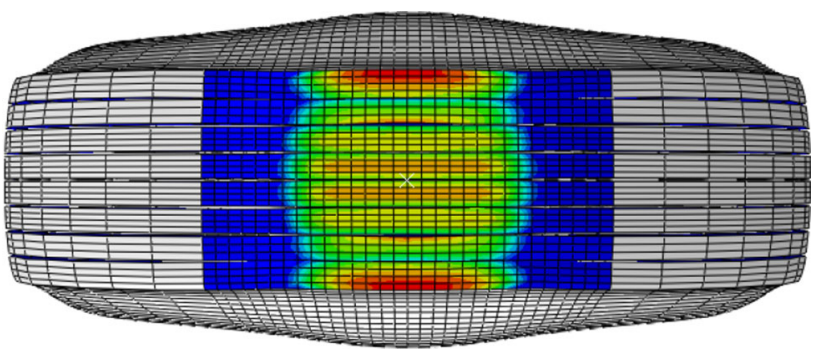

Fig. 2 Contact mark of walking wheel under the action of $5500 \mathrm{~kg}$ static pressure

According to the width of the finger-band and the speed of the vehicle, a single wheel passes through the fingerband at constant speed in $0.0122 \mathrm{~s}$. It can be assumed that the $\gamma$ is uniformly changed during this period of time. In the first $0.0061 \mathrm{~s}, \gamma$ varies from 1 to 0.75 , and in the following $0.0061 \mathrm{~s}$, from 0.75 to 1 . Assuming that the bogie is not displaced vertically, the vertical load of the bogie changes from 0 to $13,750 \mathrm{~N}$ in the first $0.061 \mathrm{~s}$ and from 13,750 to 0 in the following $0.061 \mathrm{~s}$.

According to simple dynamic calculation, under this action, the bogie moves downward vertically $1.24 \times 10^{-4} \mathrm{M}$ in $0.0122 \mathrm{~s}$, and the effect of this displacement on the vertical load of the tire is $155 \mathrm{~N}$, which is approximately $1 \%$, compared with $13,750 \mathrm{~N}$, and so it can be neglected. Therefore, it is considered that the force acting on the tire is mainly caused by the change in the vertical stiffness of the tire when the vertical center of the tire moves up and down.

So, by dynamics calculation, when the car body passes through the finger-shaped plate area, the tire force operation is as follows: the vertical acceleration of the tire (downward) is increased from 0 to $10 \mathrm{~m} / \mathrm{s}^{2}$ in the first $0.0061 \mathrm{~s}$, and the vertical acceleration of the tire (downward) is reduced from 10 to $0 \mathrm{~m} / \mathrm{s}^{2}$ in the following $0.0061 \mathrm{~s}$.

\section{Walking Tires and Finger-band Dynamic Model Building}

In this paper, ADAMS, one multi-body dynamics software, is used to calculate the wheel-rail coupling dynamics of straddle-type monorail vehicle.

For monorail vehicle, the bogie is the core of its structure, and also the key component of the wheel and rail contact force transmission. According to the mass distribution law of bogie and car body (Table 3), the transmission of bogie and vehicle, the transmission of tire and bogie, and the interaction between tire and rail surface, the model of bogie, vehicle and road model (Table 4) is built shown in Fig. 3, on the basis of fully considering the force of the bogie. In order to simulate the actual road surface, the road roughness is classified as class A according to the road spectrum in the USA.

The average speed of Chongqing monorail line 3 is about $43 \mathrm{~km} / \mathrm{h}$, so $43 \mathrm{~km} / \mathrm{h}$ is used as the running speed of single track vehicle.

In order to simulate the force acting on the finger plate of a monorail train, an equivalent deformation force is added to all the axles of the vehicle to replace the equivalent stiffness change of the tire. The action, time, magnitude and direction of force are discussed in the second part of this paper. Since the length of the PC track beam is 22-24 m, the acting force is applied in accordance with the interval between each $2 \mathrm{~s}$ of the same set of tires passing through a finger plate. According to kinematics calculation, the force conditions of the two bogies, a total of four axles, are the same, and they will pass the same finger-band at the same time intervals. As the calculation is too large, only four finger-bands are selected for dynamic simulation modeling.

\section{Simulation}

Because the vehicle movement is applied on the tire, the vehicle is uniformly accelerated from 0 , reaching a steady speed $43 \mathrm{~km} / \mathrm{s}$ after $3 \mathrm{~s}$. As this drive will affect the 
Table 3 Parameter of vehicle

\begin{tabular}{ll}
\hline Length/m & 15.5 \\
Width/m & 2.9 \\
The height between the top of the air conditioner to the track surface $/ \mathrm{m}$ & 3.76 \\
The mass of vehicle under full load /t & 41.6 \\
Average speed of line segments $/ \mathrm{m} / \mathrm{s}$ & 11.94 \\
The mass of bogie/t & 5.5 \\
\hline
\end{tabular}

Table 4 Parameter of the track

\begin{tabular}{ll}
\hline Width of running track/m & 0.85 \\
Side height/m & 1.5 \\
The Power density function of running track Gd & $1.5 \mathrm{e}-6$ \\
\hline
\end{tabular}
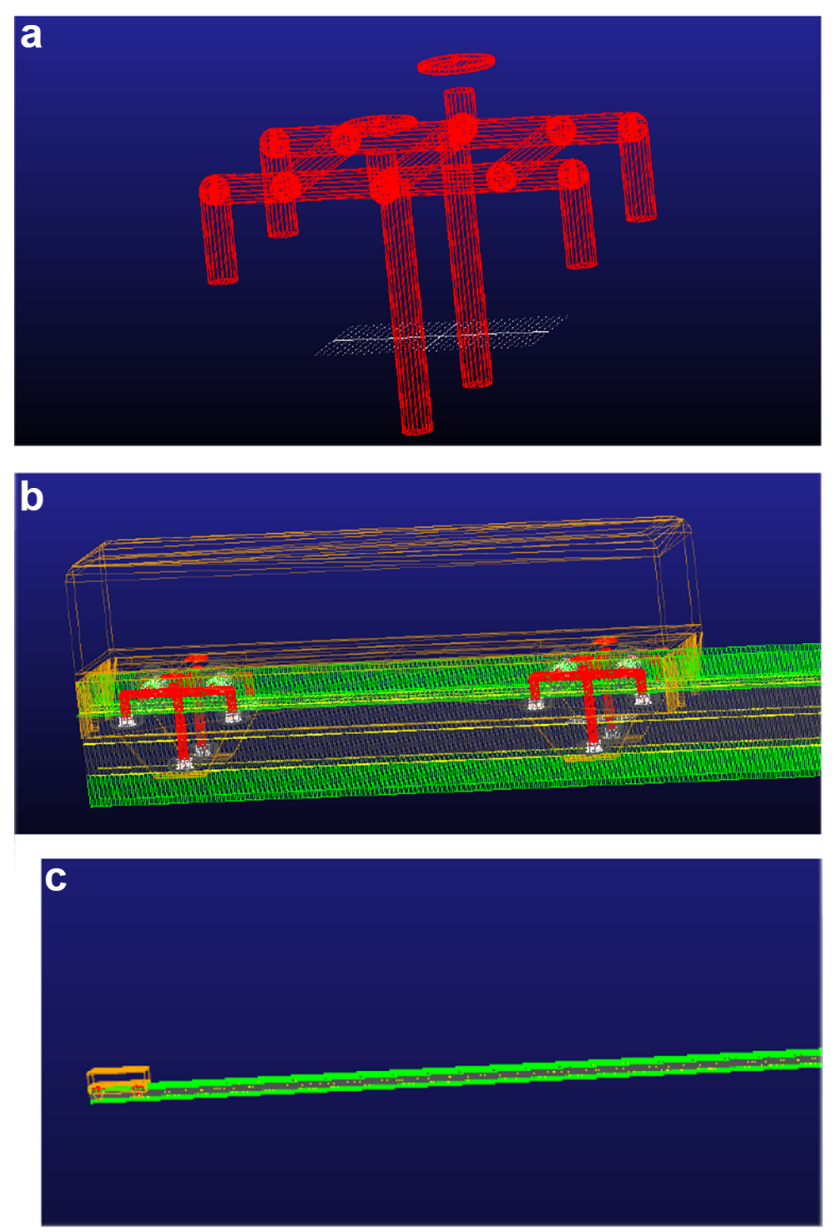

Fig. 3 Wheel-rail coupling dynamic model in Adams. a Bogie model, b vehicle model, $\mathbf{c}$ whole vehicle routing model

vertical motion of the vehicle in a short time, thus, the force on the front axle of the front bogie is applied from the $5 \mathrm{~s}$ to the end of the $11 \mathrm{~s}$, and a total of four finger plate sections are experienced, the force acting on the other axles moves in time according to the kinematic equations. The simulation ends at $14 \mathrm{~s}$.
As shown in Fig. 4, the simulation results show that the force of the front and rear bogies is symmetrical, that is, the vertical motion of the front axle of the front bogie and the front axle of the rear bogie is basically similar, and the rear axle of the front bogie is basically similar to the rear axle of the rear bogie. As the bogie structure is rigid, the the tire of the front axis through the finger-band, it causes the rear axle to produce an upward acceleration, as a result, the rear axle produces a downward force during the acceleration of the finger-band.

Because of the similarity of the vertical motion of the four axles, the vertical acceleration of the first axis of the front bogie (Fig. 4a) is only analyzed here. From its timedomain characteristic curve, its vertical acceleration is mainly within $+5 \mathrm{~m} / \mathrm{s}^{2}$ and fully meets the large acceleration at a downward rate every $2 \mathrm{~s}$. The acceleration of other time is due to the random vibration produced by the road roughness, and from the FFT it can be obtained by the frequency-domain characteristic curve shown in Fig. 5

As shown in Fig. 5, the vertical vibration of the bogie is mainly concentrated in the $2.5-13 \mathrm{~Hz}$. If the frequency is too large or too small, the contribution is very low. In addition, its main frequency is about $4 \mathrm{~Hz}$, and its contribution is about $0.43 \mathrm{~m} / \mathrm{s}^{2}$, it can be considered as the result of wheel-rail coupling in the finger-band region, and other parts should be mainly due to the random vibration produced by the road roughness.

Chongqing Orbital Corporation has entrusted the third party to do a real vertical running test of monorail train, and Fig. 6 shows the data of the vertical vibration acceleration of the center point of the front bogie front axle in the middle vertical (a vertical which is not the one placed in head or end of the monorail train). The data in Fig. 6a are the straight line to the time-domain vibration period, its ordinate unit is $\mathrm{m} / \mathrm{s} 2$, and the horizontal axis is the sampling point. The sampling frequency is $2000 \mathrm{~Hz}$. The data in Fig. $6 \mathrm{~b}$ is from FFT transform to the data of Fig. 6a.

It can be seen from Fig. $6 \mathrm{a}$, the front axle is still producing a larger impact every $2 \mathrm{~s}$ or so, about $10 \mathrm{~m} / \mathrm{s}^{2}$ in size and downward in direction, that should mean the impact of the finger-band on the tires. Figure $6 \mathrm{~b}$ shows that the vibration frequency of the axle should be $3-13 \mathrm{~Hz}$, in which the main frequency is about $4 \mathrm{~Hz}$, and its contribution is about $0.8 \mathrm{~m} / \mathrm{s}^{2}$, and the rest should be mainly 
Fig. 4 Movement of the four bogies in time domain. a Vertical acceleration of front bogie front axle, $\mathbf{b}$ vertical acceleration of front bogie rear axle, $\mathbf{c}$ vertical acceleration of rear bogie front axle, $\mathbf{d}$ vertical acceleration of rear bogie rear axle a

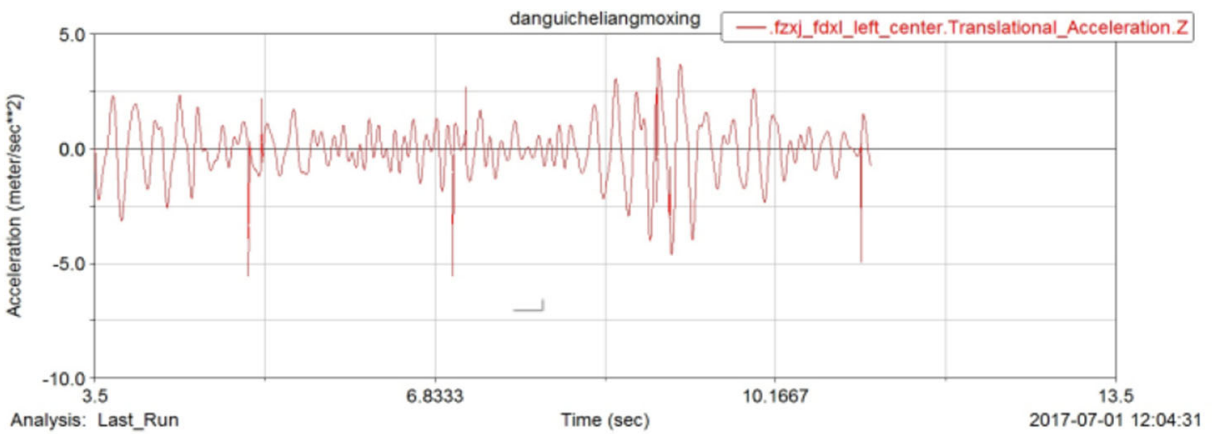

b

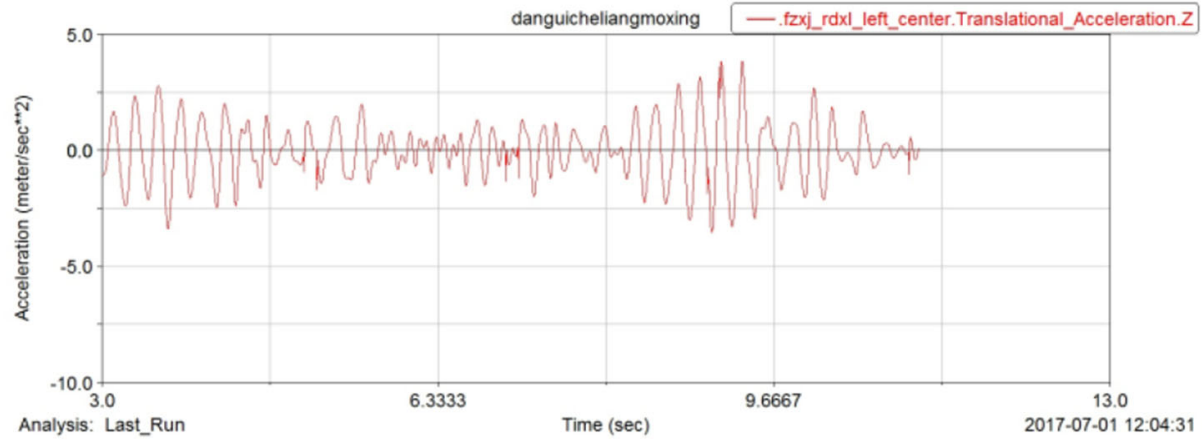

C

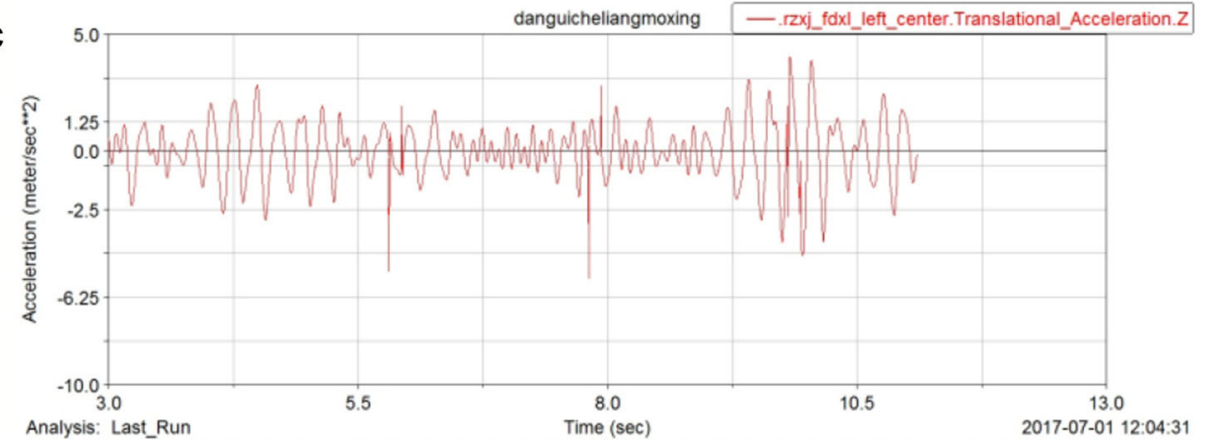

d

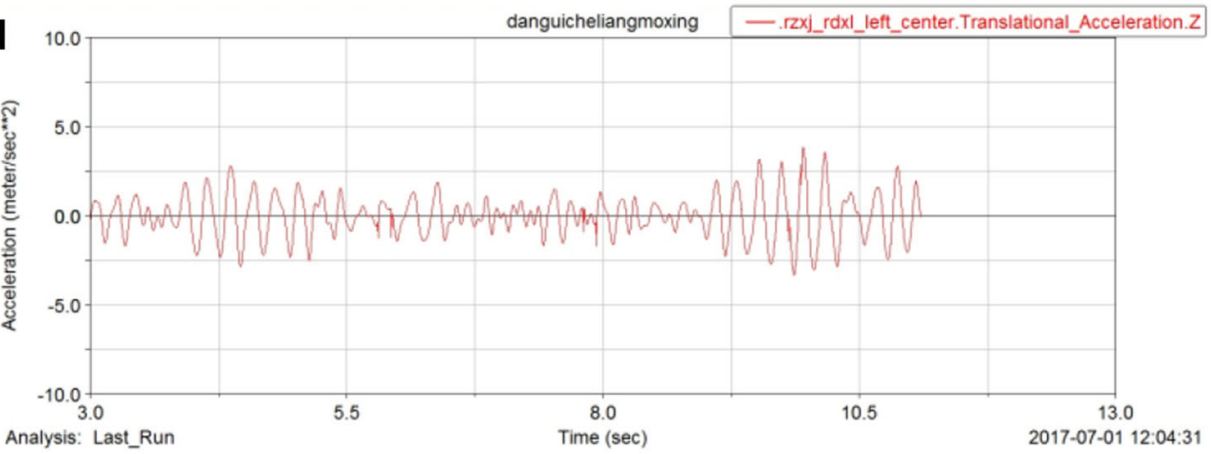




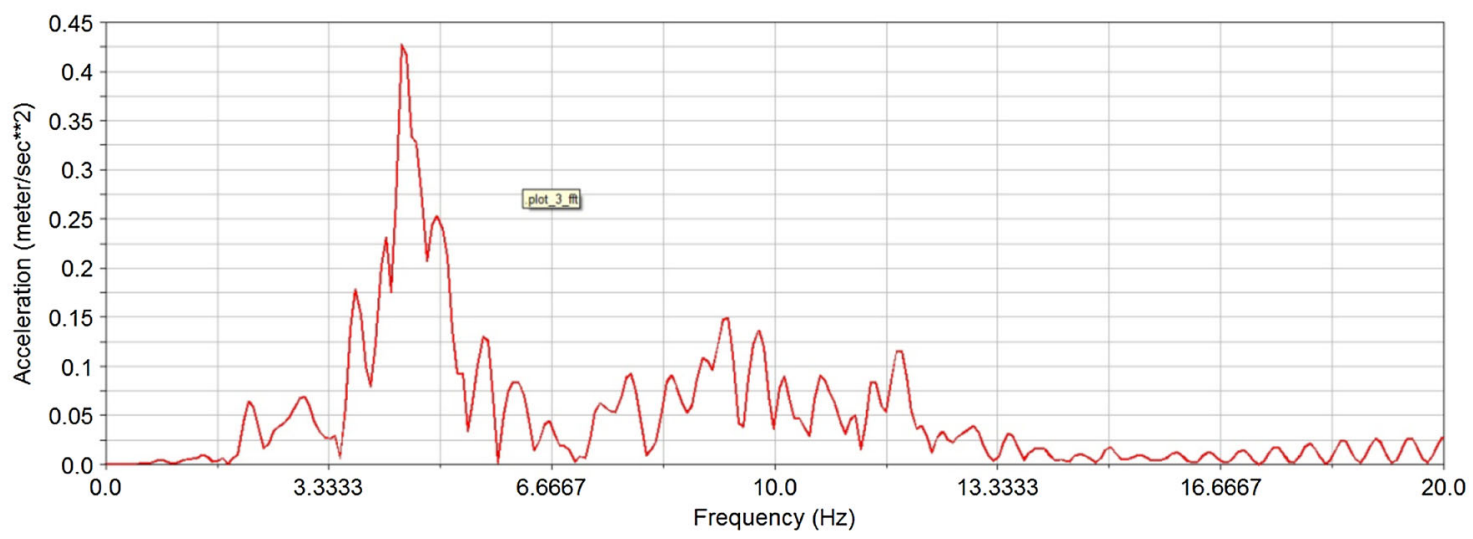

Fig. 5 FFT transformation results of vertical acceleration of front bogie front axle

Fig. 6 Data of the vertical vibration acceleration of the center point of the front bogie front axle in the middle vertical. a Time-domain vibration, $\mathbf{b}$ data after FFT
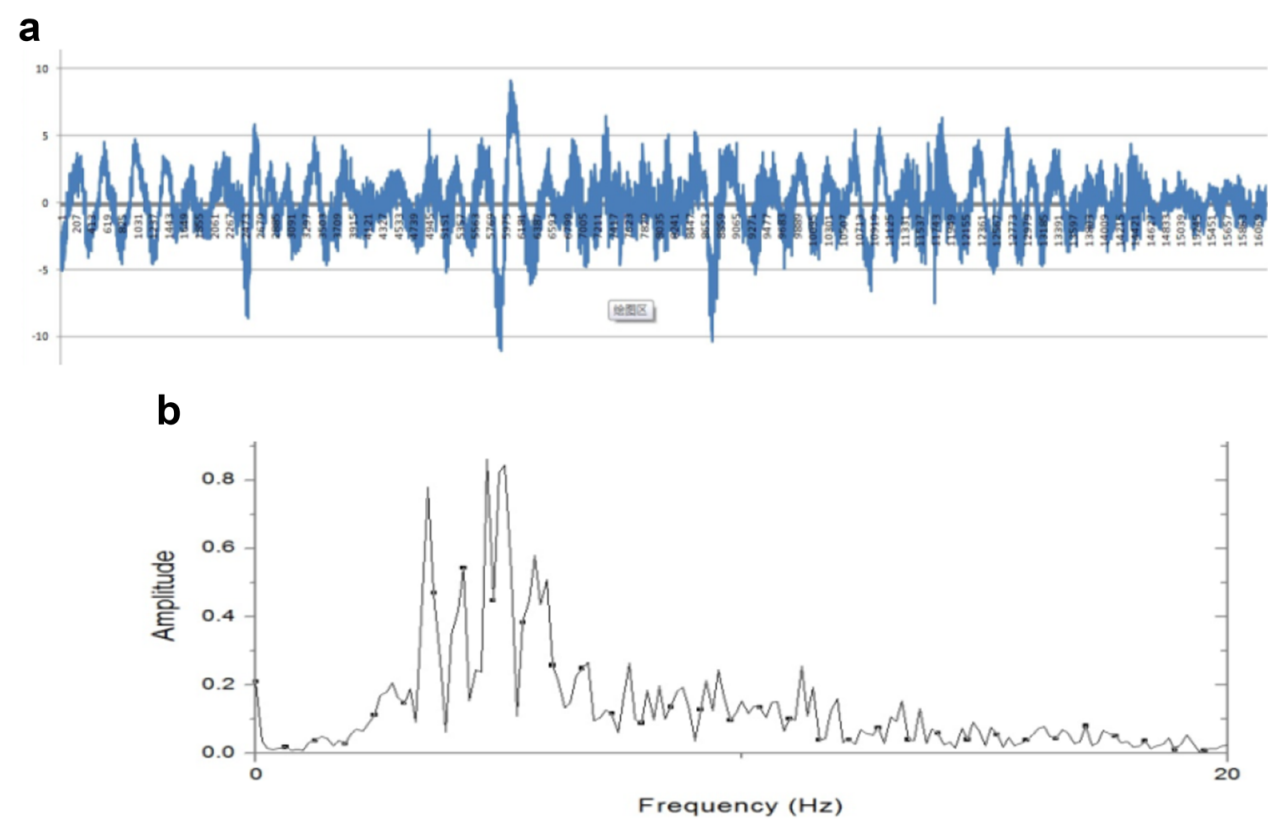

caused by road roughness. This is very similar to the structure calculated by the kinetic model used in this paper.

\section{Conclusion and Future Work}

In this paper, the force and dynamic response of straddletype monorail walking wheel passing through the finger plate are studied. An equivalent stiffness method for dealing with the dynamics of nonlinear mechanical materials such as rubber tires is presented, a dynamic model for the force and dynamic response of finger-shaped plate and walking tire is designed, their simulation models are constructed, the dynamic simulation calculation is carried out by using ADAMS, the results are in good agreement with the measured data, and the validity of the kinetic model is verified. According to the experimental data, this paper proved that finger-band is the maximum excitation source of vertical vibration of monorail vehicle by simulation, we can reduce the effective stiffness of the tire when crossing the band by change refers to the geometric structure and parameters of the finger-band, it has great effect to reduce the vertical vibration of vehicle.

There are still some shortcomings.

First, due to the lack of track beam road roughness test data, the simulation can only use the US road spectrum in the mean of grade A road roughness as ordinary excitation, it makes the measured values have certain discrepancy in the PC beam area compared with the simulation data, and it influences the superposition of acceleration at the fingerband area.

Second, for uneven deformation of the tire at the finger plate, due to the lack of necessary experimental data, shear stress between adjacent structures of the rubber body is 
neglected, only the geometry relation is processed simply, so that the simulation data and the measured value have certain discrepancy in the finger-band area, especially in frequency spectrum analysis, the contribution of each frequency vibration is different.

Acknowledgements Fund Project: National Natural Science Foundation of China. Project Name: Research on the Mechanism and Control Method of Monorail Trains Running Tires' Shoulder Wear. Project No. 51475062.

Open Access This article is distributed under the terms of the Creative Commons Attribution 4.0 International License (http://crea tivecommons.org/licenses/by/4.0/), which permits unrestricted use, distribution, and reproduction in any medium, provided you give appropriate credit to the original author(s) and the source, provide a link to the Creative Commons license, and indicate if changes were made.

\section{References}

1. Zhong J, Du Z, He X (2013) Turnout structure and analysis of monorail vehicle. People Communications Press, London

2. Zhai W (2007) Vehicle track coupling dynamics. Science Press, Beijing

3. Yang S, Chen L, Li S (2012) Research on vehicle road coupling system dynamics. Science Press, Beijing

4. Penn GR (1968) An analog model of a powerplant coupled to a real car for structure dynamic development. Automotive engineering congress
5. Lyon D (1972) The calculation of track forces due to dipped rail joint, wheel flats and rail weids. The second ORE colloquium on technical computer programs

6. Jenkins H (1974) The effect of track and vehicle parameters on wheel/rail vertical dynamic forces. Railw Eng J 3(1):2-16

7. Markow J, Hedrick K (1988) Analyzing the interactions between dynamic vehicle loads and highway pavements. Transp Rec 1196:161-169

8. Myers L (1999) Measurement of contact stress for different truck tire types to evaluate their influence on near surface cracking and rutting. Transp Rec 1655:175-184

9. Li S, Yang S (2006) Primary resonance of a vehicle suspension with nonlinear stiffness and nonlinear damping. In: The 8th biennial ASME conference of engineering systems design and analysis, Torino, Italy

10. Li S, Yang S (2007) Dynamical analysis of a nonlinear vehicle suspension system under harmonic excitation. Dyn Contin Discrete Impuls Syst Ser B Appl Algorithms 14(Suppl 5):169-173

11. Li S, Yang S (2006) Primary resonance of nonlinear vehicle suspension using improved Bingham model. J Vib Shock 25(4):109-111, 128

12. Li S, Yang S, Li H (2007) Semi-active control of vehicle suspension based on ADAMS-MATLAB joint simulation. J Syst Simul 19(10):2304-2307

13. Zhang K, Zhu E-y (2008) Simulation analysis for the nonlinear seismic response of seismically isolated continuous bridge. In: 2008 international workshop on modelling, simulation and optimization. Computer Society Press, pp 364-367

14. Zhang K (2012) Vehicle bridge coupled vibration analysis of curved bridge with monorail. Beijing Jiaotong University, Beijing 